Article

\title{
Temperature Dependence on Density, Viscosity, and Electrical Conductivity of Ionic Liquid 1-Ethyl-3-Methylimidazolium Fluoride
}

\author{
Fengguo Liu ${ }^{1}$, Xiongwei Zhong ${ }^{2}$, Junli Xu ${ }^{3}$, Ali Kamali ${ }^{1}$ and Zhongning Shi ${ }^{1 \text {,* }}$ \\ 1 School of Metallurgy, Northeastern University, No. 3-11, Wenhua Road, Shenyang 110819, China; \\ liufg@smm.neu.edu.cn (F.L.); ali@smm.neu.edu.cn (A.K.) \\ 2 Department of Materials Science and Engineering, Southern University of Science and Technology, \\ No. 1088, Xueyuanda Road, Shenzhen 518055, China; zhongxw@mail.sustc.edu.cn \\ 3 School of Science, Northeastern University, No. 3-11, Wenhua Road, Shenyang 110819, China; \\ jlxu@mail.neu.edu.cn \\ * Correspondence: shizn@smm.neu.edu.cn; Tel.: +86-024-8368-6381
}

Received: 29 January 2018; Accepted: 27 February 2018; Published: 1 March 2018

\begin{abstract}
Ionic liquids are considered environmentally friendly media for various industrial applications. Basic data on physicochemical properties are significant for a new material, in terms of developing its potential applications. In this work, 1-ethyl-3-methylimidazolium fluoride ([EMIm]F) ionic liquid was synthesized via an anion metathesis process. Physical properties including the density, viscosity, electrical conductivity, and thermal stability of the product were measured. The results show that the density of [EMIm]F decreases linearly with temperature increases, while dynamic viscosity decreases rapidly below $320 \mathrm{~K}$ and the temperature dependence of electrical conductivity is in accordance with the VFT (Vogel-Fulcher-Tammann) equation. The temperature dependence of the density, conductivity, and viscosity of [EMIm]F can be expressed via the following equations: $\rho=1.516-1.22 \times 10^{-3} T, \sigma_{\mathrm{m}}=4417.1 \mathrm{exp}[-953.17 /(T-166.65)]$ and $\eta=2.07 \times 10^{-7} \exp \left(-5.39 \times 10^{4} / T\right)$, respectively. [EMIm] F exhibited no clear melting point. However, its glass transition point and decomposition temperature are $-71.3^{\circ} \mathrm{C}$ and $135^{\circ} \mathrm{C}$, respectively.
\end{abstract}

Keywords: ionic liquids; imidazolium; viscosity; conductivity; density

\section{Introduction}

Ionic liquids (ILs) are molten salts comprised entirely of cations and anions with a melting point below $100{ }^{\circ} \mathrm{C}$. Generally, cations are organic, such as alkyl-substituted imidazolium, pyridinium, pyrrolidinium, tetraalkylammonium, and tetraalkylphosphonium. Anions can be organic or inorganic, such as halide, tetrafluoroborate, hexafluorophosphate, and bistriflimide. In earlier studies, ethylpyridinium cation was reported as an IL in the 1950s [1], N-butylpyridinium cation was reported as an IL in the 1970s [2], and 1-ethyl-3-methyl-imidazolium cation was reported as an IL in the 1980s [3]. Subsequently, ILs received increasing attention due to their extraordinary physicochemical properties including low melting point, low vapor pressure, high conductivity, and wide potential window. In recent decades in particular, ILs have been considered a promising, green medium for reactive metal electrodeposition, replacing high-temperature molten salts [4-10].

Numerous studies have focused on designing new ILs and on the relationship between the phase behavior and molecular structure, in order to clarify the nature of ILs and expand their applications [11-15].

Fundamental data on physical and chemical properties are very important for IL design and for the exploration of new applications. So far, many experimental or simulated studies on the density, 
viscosity, conductivity, thermal behavior, and solubility of pure ILs and their mixtures have appeared in the literature [16-20]. Tokuda and co-workers [21-23] systematically studied the effect of ionic structures, including anionic species, cationic species, and alkyl chain, in imidazolium cation on the physicochemical characteristics of ILs.

Alkyl-substituted imidazolium cation-based ILs have been studied extensively due to their advantages in terms of superior fluidity and conductivity. The generic structure of alkyl-substituted imidazolium-based ILs is shown in Figure 1.

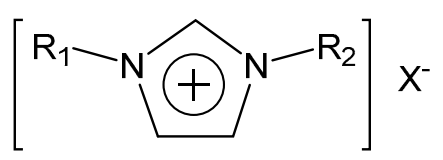

Figure 1. The generic structure of alkyl-substituted imidazolium=based ILs. $R_{1}=$ alkyl (methyl typically), $\mathrm{R}_{2}=$ alkyl, $\mathrm{X}^{-}=$anion (halide, $\mathrm{BF}_{4}^{-}, \mathrm{PF}_{6}^{-}, \mathrm{Tf}_{2} \mathrm{~N}^{-}$, typically).

For the molecular structure of alkyl-substituted imidazolium-based ILs, as shown in Figure $1, R_{1}$ is typically methyl and $R_{2}$ can generally be butyl [24-31], ethyl [32-35], or octyl [36]. Common anionic species include halide, tetrafluoroborate $\left(\mathrm{BF}_{4}^{-}\right)$, tetrafluorophosphate $\left(\mathrm{PF}_{6}{ }^{-}\right)$, bis(trifluoromethylsulfonyl)imide $\left(\mathrm{Tf}_{2} \mathrm{~N}^{-}\right)$, dicyanamide (DCA), ethylsulfate $\left(\mathrm{EtSO}_{4}\right)$, etc. Among them, ILs with a single fluoride anion are rarely reported because the syntheses of such ILs are challenging, unlike those of other halide ILs. As is known, the enhanced basicity of metal fluorides can lead to Hoffman elimination on side chains of the cationic part of the system. However, anion metathesis from other halides is accessible. Hagiwara and co-workers [37] prepared 1-ethyl-3-methyl imidazolium fluoride (EMIF.2.3HF) via the reaction of hydrogen fluoride and homologous chloride. Pagoria et al. [38] reported a method that included putting a strongly hydrogen bonded organic material in contact with an ionic liquid having a fluoride anion for the solubilization of the strongly hydrogen bonded organic material. [EMIm]F and other similar imidazolium fluoride ionic liquids could be prepared using imidazolium chloride and silver fluoride as raw materials. Zhu et al. [39] synthesized a series of 1-akyl-3-methylimidazolium fluorides via the reaction of silver fluoride with the corresponding imidazolium iodides; weak interactions between the fluoride anion and sp3-hybridized $\mathrm{C}-\mathrm{H}$ groups were observed.

So far, few studies exist on the synthesis of [EMIm]F ionic liquid, and knowledge of its physical properties is lacking. We therefore prepared [EMIm]F ionic liquid via an anion metathesis process. It could potentially be used as fluoride source for nanoparticle synthesis [40,41], as an electrolyte for metal deposition, and as a solvent for chemical processing [42]. We focused on its physical properties including density, viscosity, conductivity, and thermal stability. We investigated the temperature effects.

\section{Materials and Methods}

\subsection{Materials}

1-ethyl-3-methylimidazolium chloride ([EMIm]Cl) with 99\% purity was provided by Lanzhou Institute of Chemical Physics (Lanzhou, China). Silver fluoride with 98\% purity and analytical grade silver nitrate was purchased from Sigma Aldrich (St. Louis, MO, USA). Analytical grade sodium chloride, ethyl acetate, and methanol were purchased from Sinopharm Chemical Reagent Co., Ltd. (Shenyang, China). All the chemicals were used as received without further purification.

\subsection{Synthesis of [EMIm]F}

The reaction principle of synthesizing [EMIm]F is based on the different solubility of silver halide. The reaction equations from [EMIm] $\mathrm{Cl}$ are shown in Figure 2. 


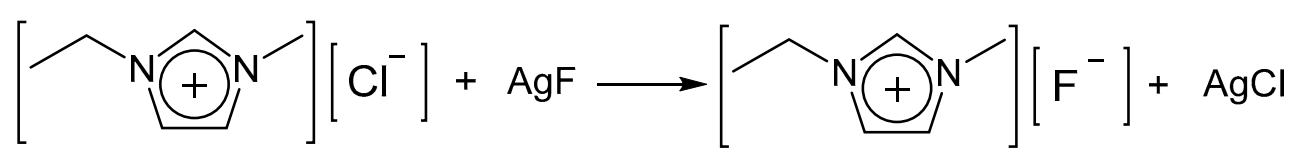

Figure 2. Synthesis process of [EMIm]F.

The synthesis procedure of [EMIm]F is as follows. (1) Twenty-five milliliters of $2.76 \mathrm{M}$ [EMIm]Cl aqueous solution and $20 \mathrm{~mL}$ of $3.45 \mathrm{M} \mathrm{AgF}$ aqueous solution (mole ratio of [EMIm] Cl/ $\mathrm{AgF}$ is 1:1) were mixed. A white precipitate was observed, indicating that the metathesis reaction began rapidly. (2) The mixture was kept for $24 \mathrm{~h}$ under stirring. Subsequently, the liquid was separated from the precipitate via filtration. (3) The filtrate was dried for $48 \mathrm{~h}$ under vacuum conditions and a viscous liquid, [EMIm]F, was obtained. (4) The product was weighed, and the yield of [EMIm]F was found to be $95 \sim 98 \%$. (5) In order to check the impurities removal and the purity of [EMIm]F, two samples of the final product were titrated via $\mathrm{AgNO}_{3}$ and $\mathrm{NaCl}$, respectively. No precipitation indicated that $\mathrm{Cl}^{-}$and $\mathrm{Ag}^{+}$ions were removed completely.

\subsection{Physical Properties of [EMIm]F}

The physical properties of [EMIm]F were also examined. To avoid the influence of water, the measurements of density and conductivity were carried out in a glove box full of argon gas. The density was measured via $10 \mathrm{~mL}$ pycnometer and the uncertainty of the measurements was estimated to be better than $\pm 5 \times 10^{-5} \mathrm{~g} \cdot \mathrm{cm}^{-3}$. The conductivity was measured via the fixed conductivity cell method, with an uncertainty of $\pm 3 \%$ calibrated by a standard sodium chloride solution. Furthermore, viscosity was measured via the rotation method on a Brookfield DV-2T viscometer (rotor model SC 4-18, vertical cryostat tank DC0506N), with a nominal uncertainty of $\pm 2 \%$. The thermal stability of [EMIm]F was measured via a differential scanning calorimeter (DSC, NETZSCH, STA449 F3) in a nitrogen atmosphere at a temperature range of $-160{ }^{\circ} \mathrm{C}$ to $200{ }^{\circ} \mathrm{C}$ and a heating rate of $10^{\circ} \mathrm{C} / \mathrm{min}$.

\section{Results and Discussion}

All the experimental data are available in the Supplementary Materials. Tables S1-S3 show density, viscosity and electrical conductivity of [EMIm]F at different temperatures, respectively. The density of [EMIm]F was measured for temperatures between $303.15 \mathrm{~K}$ and $353.15 \mathrm{~K}$. The temperature dependence of the density of [EMIm]F is shown in Figure 3. Meanwhile, the densities of ILs with the same cationic group and different anionic groups were also compared [43-46]. Figure 3 shows that the density of [EMIm]F decreases linearly with the increase of temperature for the other ILs. At a certain temperature, the density of [EMIm]F is higher than that of [EMIm][OAc] and [EMIm][DCA], and

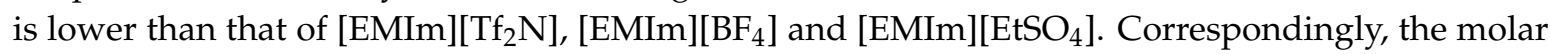
volume, calculated by dividing the molar mass by the density, increases linearly with the increase of temperature. The relationships between the density, molar volume, and temperature can be described by the following fitting equations:

$$
\begin{gathered}
\rho=1.516-1.22 \times 10^{-3} \mathrm{~T} \\
V_{\mathrm{m}}=76.21+0.1296 \mathrm{~T} .
\end{gathered}
$$

To study the volume changes of a pure liquid caused by the temperature at a constant pressure, a parameter, $\alpha$, known as the thermal expansion coefficient, is defined as

$$
\alpha=\frac{1}{V}\left(\frac{\partial V}{\partial T}\right)_{p}=-\frac{1}{\rho}\left(\frac{\partial \rho}{\partial T}\right)_{p}=\frac{1}{V_{m}}\left(\frac{\partial V_{m}}{\partial T}\right)_{p},
$$

where the subscript $p$ indicates constant pressure.

According to the calculus principle, Equation (3) can also be expressed as 


$$
\alpha=\left(\frac{\partial \ln V}{\partial T}\right)_{p}=-\left(\frac{\partial \ln \rho}{\partial T}\right)_{p}=\left(\frac{\partial \ln V_{m}}{\partial T}\right)_{p} .
$$

As we discussed above, both the density and molar volume have a linear relation with the temperature. Namely, $(\partial \rho / \partial T)_{p}$ and $\left(\partial V_{m} / \partial T\right)_{p}$ are constant. The thermal expansion coefficient $\alpha$ varies with the density according to Equation (3). However, $\alpha$ is a constant from Equation (4) because the plot of $\ln \rho$ versus $T$ is also linear. Actually, the two perspectives are not so conflicting due to different linear relations supposed in a rational scope $\left(R^{2}>0.99\right)$ for the two equations. In the literature, both alternatives were reported in order to evaluate the volume expansivity for ILs $[44,47,48]$. For simplification, our work considers the thermal expansion coefficient of [EMIm]F a constant from Equation (4): $1.09 \times 10^{-3} \mathrm{~K}^{-1}$.

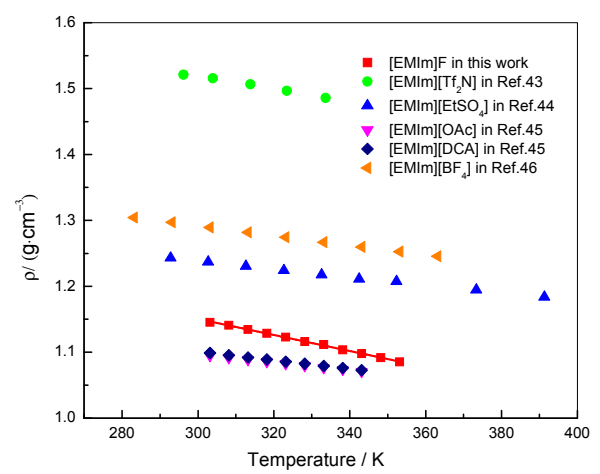

Figure 3. Temperature dependence of the densities of [EMIm]F and similar ILs.

The dynamic viscosity of [EMIm]F was measured via a DV-2T viscometer. The viscosities of ILs with the same cationic group and different anionic groups were compared, as shown in Figure 4. The viscosity of [EMIm]F is obviously larger than that of other ILs below $320 \mathrm{~K}$, and decreases sharply with the temperature increase. The viscosity of [EMIm]F approaches that of other ILs above $320 \mathrm{~K}$. As is known, the viscosity of ILs is mainly dependent on the combination of hydrogen bonds and van der Waals forces. The viscosity variation of [EMIm]F indicates that the interaction forces between the cation and anion are susceptible to temperature. In general, the relationship between temperature and viscosity can be expressed as an exponential equation, commonly known as an Arrhenius-type equation:

$$
\eta=\eta_{\infty} \exp \left(-\frac{E_{a}}{R T}\right)
$$

where $R$ is the ideal gas constant, $\eta_{\infty}$ is the viscosity at the infinite temperature, and $E_{\mathrm{a}}$ is the apparent activation energy. According to the fitting results, the characteristic parameters of [EMIm]F can be obtained: $\eta_{\infty}=2.07 \times 10^{-7} \mathrm{mPa} \cdot \mathrm{s}, E_{\mathrm{a}}=-5.39 \times 10^{4} \mathrm{~J} \cdot \mathrm{mol}^{-1}$.

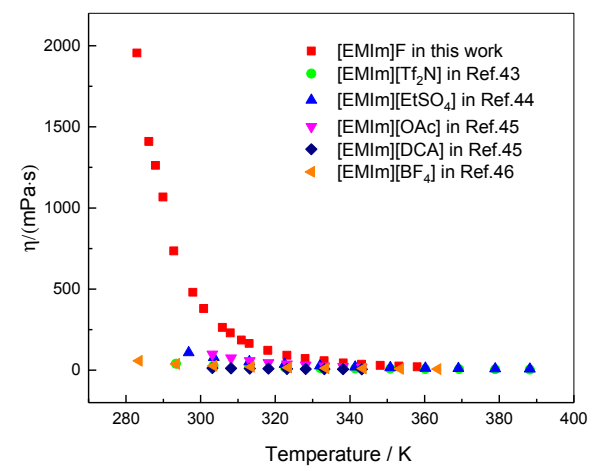

Figure 4. Viscosity of [EMIm]F and similar ILs as a function of temperature. 
The conductivity of ionic liquids is a parameter reflecting the current transporting capacity. The conductivity of [EMIm]F as a function of temperature was studied, as shown in Figure 5. As can be seen, the conductivity of [EMIm]F increases with the increase in temperature. We fitted the relationship between the conductivity and temperature using a VFT (Vogel-Fulcher-Tammann) equation:

$$
\sigma=\sigma_{0} \exp \left[-\mathrm{B} /\left(T-\mathrm{T}_{0}\right)\right],
$$

where $\sigma_{0}\left(\mathrm{mS} \cdot \mathrm{cm}^{-1}\right), \mathrm{B}(\mathrm{K})$, and $\mathrm{T}_{0}(\mathrm{~K})$ are constants. The fitting parameters are obtained as follows: $\sigma_{0}=4417.1 \mathrm{mS} \cdot \mathrm{cm}^{-1}, \mathrm{~B}=953.17 \mathrm{~K}, \mathrm{~T}_{0}=166.65 \mathrm{~K}$.

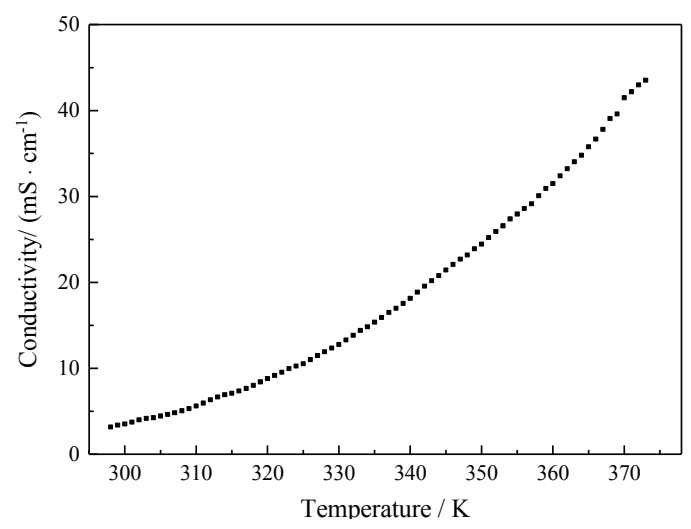

Figure 5. Electrical conductivity of [EMIm]F as a function of temperature.

The thermal behavior of [EMIm]F was studied via differential scanning calorimetry. The DSC curve of [EMIm]F at a cooling and heating rate of $10 \mathrm{~K} / \mathrm{min}$ is shown in Figure 6. During cooling from 50 to $-150{ }^{\circ} \mathrm{C}$, we could only observe an exothermic peak at $-71.3^{\circ} \mathrm{C}$, corresponding to the glass transition. In the heating process from -150 to $200{ }^{\circ} \mathrm{C}$, two endothermic peaks were found. One is the glass transition point, which was also observed during the cooling process. The other is assigned to the decomposition temperature around $135^{\circ} \mathrm{C}$. No melting point on the DSC curve was observed, as is the case for many other ionic liquids. It has been reported that the melting point of many ionic liquids is uncertain because they can undergo considerable supercooling [49-51]. The temperature of the phase change can differ considerably depending on whether the sample is heated or cooled [52].

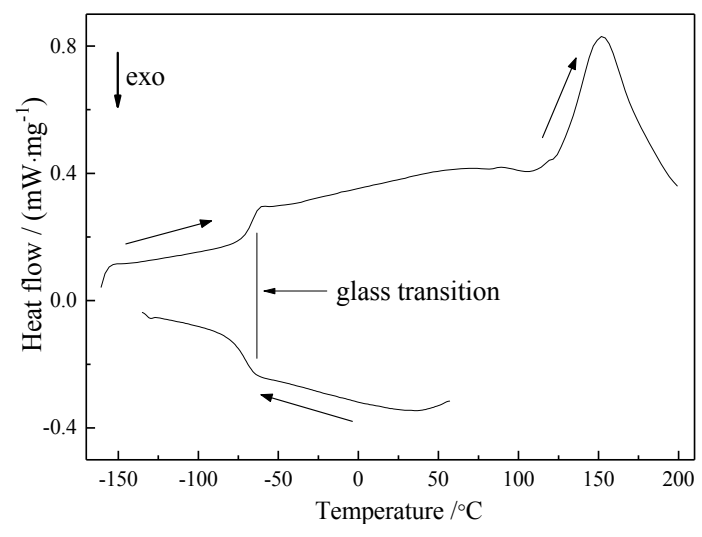

Figure 6. Differential scanning calorimeter (DSC) curve of [EMIm]F at the cooling and heating rate of $10 \mathrm{~K} / \mathrm{min}$.

\section{Conclusions}

[EMIm]F was synthesized via an anion metathesis process using [EMIm] $\mathrm{Cl}$ and $\mathrm{AgF}$ as raw materials. The density, conductivity, dynamic viscosity, and the thermal stability of [EMIm]F 
were studied. With the increase of temperature, the density of [EMIm]F decreased linearly, while the viscosity and conductivity of [EMIm]F increased. The corresponding temperature dependence equations were summarized. The thermal analysis indicated that [EMIm]F had no clear melting point, while its glass transition point and decomposition temperature were $-71.3^{\circ} \mathrm{C}$ and $135^{\circ} \mathrm{C}$, respectively.

Supplementary Materials: The following are available online at www.mdpi.com/2076-3417/8/3/356/s1, Table S1: Density of [EMIm]F at different temperatures. Table S2: Viscosity of [EMIm]F at different temperatures. Table S3: Conductivity of [EMIm]F at different temperatures.

Acknowledgments: The authors acknowledge financial support from the National Key R \& D Program of China (No. 2017YFC0805101), the National Natural Science Foundation of China (No. 51574071, 51322406), the Fundamental Research Funds for the Central Universities (No. N162503001), and the NEU Postdoctoral Foundation (No. 20170307).

Author Contributions: Zhongning Shi. conceived and designed the experiments; Fengguo Liu and Xiongwei Zhong performed the experiments; Fengguo Liu, Ali Kamali, and Junli Xu analyzed the data; Fengguo Liu wrote the paper.

Conflicts of Interest: The authors declare no conflict of interest.

\section{References}

1. Hurley, F.H.; Weir, T.P. The Electrodeposition of Aluminum from Nonaqueous Solutions at Room Temperature. J. Electrochem. Soc. 1951, 98, 207-212. [CrossRef]

2. Chum, H.L.; Koch, V.R.; Miller, L.L.; Osteryoung, R.A. Electrochemical scrutiny of organometallic iron complexes and hexamethylbenzene in a room temperature molten salt. J. Am. Chem. Soc. 1975, 97, 3264-3265. [CrossRef]

3. Wilkes, J.S.; Levisky, J.A.; Wilson, R.A.; Hussey, C.L. Dialkylimidazolium chloroaluminate melts: A new class of room-temperature ionic liquids for electrochemistry, spectroscopy and synthesis. Inorg. Chem. 1982, 21, 1263-1264. [CrossRef]

4. Wasserscheid, P.; Keim, W. Ionic liquids-new solution for transition metal catalysis. Angew. Chem. Int. Ed. 2000, 39, 3772-3789. [CrossRef]

5. Zhang, Q.; Wang, Q.; Zhang, S.; Lu, X.; Zhang, X. Electrodeposition in Ionic Liquids. Chem. Phys. Chem. 2016, 17, 335-351. [CrossRef] [PubMed]

6. Vaughan, J.; Tu, J.; Dreisinger, D. Ionic liquid electrodeposition of reactive metals. Miner. Process. Extr. Metall. 2008, 117, 113-117. [CrossRef]

7. Xu, C.; Hua, Y.; Zhang, Q.; Li, J.; Lei, Z.; Lu, D. Electrodeposition of Al-Ti alloy on mild steel from $\mathrm{AlCl}_{3}-\mathrm{BMIC}^{-}$ ionic liquid. J. Solid State Electr. 2017, 21, 1349-1356. [CrossRef]

8. Zhang, M.; Kamavarum, V.; Reddy, R.G. New electrolytes for aluminum production: Ionic liquids. JOM 2003, 55, 54-57. [CrossRef]

9. Liu, A.; Shi, Z.; Reddy, R. Electrodeposition of Pb from PbO in urea and 1-butyl-3-methylimidazolium chloride deep eutectic solutions. Electrochim. Acta 2017, 251, 176-186. [CrossRef]

10. Li, M.; Gao, B.; Liu, C. $\mathrm{AlCl}_{3}$ /amide ionic liquids for electrodeposition of aluminium. J. Solid State Electr. 2016, 21, 1-8.

11. Zou, F.; Yu, X.; Zhang, J.; Cheng, N.; Huang, X. Electropolymerization in a novel proton functionalized room temperature ionic liquid anilinium acetate. Synth. Met. 2015, 204, 76-83. [CrossRef]

12. Huddleston, J.G.; Willauer, H.D.; Swatloski, R.P.; Visser, A.E.; Rogers, R.D. Room temperature ionic liquids as novel media for 'clean' liquid-liquid extraction. Chem. Commun. 1998, 16, 1765-1766. [CrossRef]

13. Björling, M.; Bair, S.; Mu, L.; Zhu, J.; Shi, Y. Elastohydrodynamic Performance of a Bio-Based, Non-Corrosive Ionic Liquid. Appl. Sci. 2017, 7, 996. [CrossRef]

14. Zheng, Y.; Zheng, Y.; Wang, Q.; Wang, Z.; Tian, D. Density and Viscosity of Binary Mixtures of 1-Ethyl-3-methylimidazolium Heptachlorodialuminate and Tetrachloroaluminate Ionic Liquids. J. Chem. Eng. Data 2017, 62, 4006-4014. [CrossRef]

15. Jacquemin, J.; Husson, P.; Mayer, V.; Cibulka, I. High-Pressure Volumetric Properties of Imidazolium-Based Ionic Liquids: Effect of the Anion. J. Chem. Eng. Data 2007, 52, 2204-2211. [CrossRef]

16. Anuar, N.K.; Subban, R.H.Y.; Mohamed, N.S. Properties of PEMA-NH4CF3SO3 Added to BMATSFI Ionic Liquid. Materials 2012, 5, 2609-2620. [CrossRef] 
17. Grothe, D.C.; Meyer, W.; Janietz, S. Acrylate Functionalized Tetraalkylammonium Salts with Ionic Liquid Properties. Molecules 2012, 17, 6593-6604. [CrossRef] [PubMed]

18. Fan, X.H.; Chen, Y.P.; Su, C.S. Density and Viscosity Measurements for Binary Mixtures of 1-Ethyl-3-methylimidazolium Tetrafluoroborate $\left([\mathrm{Emim}]\left[\mathrm{BF}_{4}\right]\right)$ with Dimethylacetamide, Dimethylformamide, and Dimethyl Sulfoxide. J. Chem. Eng. Data 2016, 61, 920-927. [CrossRef]

19. Ghatee, M.H.; Zare, M.; Moosavi, F.; Zolghadr, A.R. Temperature-Dependent Density and Viscosity of the Ionic Liquids 1-Alkyl-3-methylimidazolium Iodides: Experiment and Molecular Dynamics Simulation. J. Chem. Eng. Data 2010, 55, 3084-3088. [CrossRef]

20. Jacquemin, J.; Nancarrow, P.; Rooney, D.W.; Costa Gomes, M.F.; Husson, P.; Majer, V.; Pádua, A.A.; Hardacre, C. Prediction of Ionic Liquid Properties. II. Volumetric Properties as a Function of Temperature and Pressure. J. Chem. Eng. Data 2008, 53, 716-726. [CrossRef]

21. Tokuda, H.; Hayamizu, K.; Ishii, K.; Susan, M.A.B.H.; Watanabe, M. Physicochemical Properties and Structures of Room Temperature Ionic Liquids. 1. Variation of Anionic Species. J. Phys. Chem. B 2004, 108, 16593-16600. [CrossRef]

22. Tokuda, H.; Hayamizu, K.; Ishii, K.; Susan, M.A.B.H.; Watanabe, M. Physicochemical Properties and Structures of Room Temperature Ionic Liquids. 2. Variation of Alkyl Chain Length in Imidazolium Cation. J. Phys. Chem. B 2005, 109, 6103-6110. [CrossRef] [PubMed]

23. Tokuda, H.; Ishii, K.; Susan, M.A.B.H.; Tsuzuki, S.; Hayamizu, K.; Watanabe, M. Physicochemical Properties and Structures of Room-Temperature Ionic Liquids. 3. Variation of Cationic Structures. J. Phys. Chem. B 2006, 110, 2833-2839. [CrossRef] [PubMed]

24. Yadav, J.S.; Reddy, B.V.S.; Basak, A.K.; Narsaiah, A.V. [Bmim]BF 4 Ionic Liquid: A Novel Reaction Medium for the Synthesis of $\beta$-Amino Alcohols. Tetrahedron Lett. 2003, 44, 1047-1050. [CrossRef]

25. Chang, H.C.; Wang, T.H.; Burba, C.M. Probing Structures of Interfacial 1-Butyl-3-Methylimidazolium Trifluoromethanesulfonate Ionic Liquid on Nano-Aluminum Oxide Surfaces Using High-Pressure Infrared Spectroscopy. Appl. Sci. 2017, 7, 855. [CrossRef]

26. Zhou, Z.; He, D.L.; Yang, R.H.; Guo, Y.N.; Zhong, J.F.; Li, G.X. Electropolymerization of benzotriazole in room temperature ionic liquid [bmim]PF6. J. Appl. Electrochem. 2008, 38, 1757-1761. [CrossRef]

27. Harris, K.R.; Kanakubo, M. Self-diffusion, velocity cross-correlation, distinct diffusion and resistance coefficients of the ionic liquid [BMIM][Tf2N] at high pressure. Phys. Chem. Chem. Phys. 2015, 17, 23977. [CrossRef] [PubMed]

28. Zhang, J.; An, M.; Chen, Q.; Liu, A.; Jiang, X.; Ji, S.; Lian, Y.; Wen, X. Electrochemical Study of the Diffusion and Nucleation of Gallium(III) in [Bmim][TfO] Ionic Liquid. Electrochim. Acta 2016, 190, 1066-1077. [CrossRef]

29. Larriba, M.; Navarro, P.; García, J.; Rodríguez, F. Liquid-Liquid Extraction of Toluene from Heptane Using [emim][DCA], [bmim][DCA], and [emim][TCM] Ionic Liquids. Ind. Eng. Chem. Res. 2013, 52, 2714-2720. [CrossRef]

30. Fernández, A.; García, J.; Torrecilla, J.S.; Oliet, M.; Rodríguez, F. Volumetric, Transport and Surface Properties of [bmim][MeSO4] and [emim][EtSO4] Ionic Liquids As a Function of Temperature. J. Chem. Eng. Data 2008, 53, 1518-1522. [CrossRef]

31. Tagiuri, A.; Sumon, K.Z.; Henni, A. Solubility of carbon dioxide in three [Tf2N] ionic liquids. Fluid Phase Equilib. 2014, 380, 39-47. [CrossRef]

32. Zhao, X.; Hu, L.; Geng, Y.; Wang, Y. The structure of acidified ionic liquid [emim] $\mathrm{BF}_{4}$ and its catalytic performance in the reaction for 4,4'-MDC synthesis. J. Mol. Catal. A Chem. 2007, 276, 168-173. [CrossRef]

33. Lin, Y.F.; Sun, I.W. Electrodeposition of zinc from a Lewis acidic zinc chloride-1-ethyl-3-methylimidazolium chloride molten salt. Electrochim. Acta 1999, 46, 1169-1177. [CrossRef]

34. Horikawa, Y.; Tokushima, T.; Takahashi, O.; Hoke, H.; Takamuku, T. Correlation between Soft X-ray Absorption and Emission Spectra of the Nitrogen Atoms within Imidazolium-Based Ionic Liquids. J. Phys. Chem. B 2016, 120, 7480-7487. [CrossRef] [PubMed]

35. Alavi, S.; Thompson, D.L. Molecular dynamics studies of melting and some liquid-state properties of 1-ethyl-3-methylimidazoliumhexafluorophosphate [emim][PF6]. J. Chem. Phys. 2005, 122, 154704-154715. [CrossRef] [PubMed]

36. Afsharpour, A.; Kheiri, A. Implementation of CPA EoS for simultaneous solubility modeling of $\mathrm{CO}_{2}$ and H2S in ionic liquid [OMIM][Tf2N]. Pet. Sci. Technol. 2017, 36, 280-286. [CrossRef] 
37. Hagiwara, R.; Hirashige, T.; Tsuda, T.; Ito, Y. Acidic 1-ethyl-3-methylimidazolium fluoride: A new room temperature ionic liquid. J. Fluor. Chem. 1999, 99, 1-3. [CrossRef]

38. Pagoria, P.F.; Maiti, A.; Gash, A.; Han, T.Y.; Orme, C.; Fried, L. Ionic Liquids as Solvents. US 20090012297, 8 January 2009.

39. Zhu, Z.Q.; Jiang, M.Y.; Zheng, C.G.; Xiao, J.C. Efficient synthesis of 1-alkyl-3-methylimidazolium fluorides and possibility of the existence of hydrogen bonding between fluoride anion and C(sp3)-H. J. Fluor. Chem. 2012, 133, 160-162. [CrossRef]

40. Nuñez, N.O.; Ocaña, M. An ionic liquid based synthesis method for uniform luminescent lanthanide fluoride nanoparticles. Nanotechnology 2007, 18, 455606. [CrossRef]

41. Olchowka, J.; Suta, M.; Wickleder, C. Green synthesis of small nanoparticles of A2SiF6 (A = Li-Cs) using Ionic Liquids as Solvent and Fluorine Source: A novel simple approach without HF. Chem. Eur. J. 2017, 23, 12092-12095. [CrossRef] [PubMed]

42. Brennecke, J.F.; Maginn, E.J. Ionic liquids: Innovative fluids for chemical processing. Aiche J. 2001, 47, 2384-2389. [CrossRef]

43. Fredlake, C.P.; Crosthwaite, J.M.; Hert, D.G.; Aki, S.N. Thermophysical Properties of Imidazolium-Based Ionic Liquids. J. Chem. Eng. Data 2004, 49, 954-964. [CrossRef]

44. Jacquemin, J.; Husson, P.; Padua, A.A.H.; Majer, V. Density and viscosity of several pure and water-saturated ionic liquids. Green Chem. 2006, 8, 172-180. [CrossRef]

45. Quijada-Maldonado, E.; Boogaart, S.V.D.; Lijbers, J.H.; Meindersma, G.W.; De Haan, A.B. Experimental densities, dynamic viscosities and surface tensions of the ionic liquids series 1-ethyl-3-methylimidazolium acetate and dicyanamide and their binary and ternary mixtures with water and ethanol at $\mathrm{T}=(298.15$ to 343.15 K). J. Chem. Thermodyn. 2012, 51, 51-58. [CrossRef]

46. Shamsipur, M.; Beigi, A.A.M.; Teymouri, M.; Pourmortazavi, S.M.; Irandoust, M. Physical and electrochemical properties of ionic liquids 1-ethyl-3-methylimidazolium tetrafluoroborate, 1-butyl-3-methylimidazolium trifluoromethanesulfonate and 1-butyl-1-methylpyrrolidinium bis(trifluoromethylsulfonyl)imide. J. Mol. Liq. 2010, 157, 43-50. [CrossRef]

47. Yang, J.Z.; Lu, X.M.; Gui, J.S.; Xu, W.G. A new theory for ionic liquids-the Interstice Model Part 1. The density and surface tension of ionic liquid EMISE. Green Chem. 2004, 6, 541-543. [CrossRef]

48. Gu, Z.; Brennecke, J.F. Volume Expansivities and Isothermal Compressibilities of Imidazolium and Pyridinium-Based Ionic Liquids. J. Chem. Eng. Data 2002, 47, 339-345. [CrossRef]

49. Nishikawa, K.; Wang, S.; Katayanagi, H.; Hayashi, S.; Hamaguchi, H.; Koga, Y.; Tozaki, K. Melting and Freezing Behaviors of Prototype Ionic Liquids, 1-Butyl-3-methylimidazolium Bromide and Its Chloride, Studied by Using a Nano-Watt Differential Scanning Calorimeter. J. Phys. Chem. B 2007, 111, 4894-4900. [CrossRef] [PubMed]

50. Huddleston, J.G.; Visser, A.E.; Reichert, W.M.; Willauer, H.D.; Broker, G.A.; Rogers, R.D. Characterization and comparison of hydrophilic and hydrophobic room temperature ionic liquids incorporating the imidazoliumcation. Green Chem. 2001, 3, 156-164. [CrossRef]

51. Imanari, M.; Fujii, K.; Endo, T.; Seki, H.; Tozaki, K.; Nishikawa, K. Ultraslow Dynamics at Crystallization of a Room Temperature Ionic Liquid, 1-Butyl-3-methylimidazolium Bromide. J. Phys. Chem. B 2012, 116, 3991-3997. [CrossRef] [PubMed]

52. Ngo, H.L.; Lecompte, K.; Hargens, L.; Mcewen, A.B. Thermal properties of imidazolium ionic liquids. Thermochim. Acta 2000, 357, 97-102. [CrossRef]

(C) 2018 by the authors. Licensee MDPI, Basel, Switzerland. This article is an open access article distributed under the terms and conditions of the Creative Commons Attribution (CC BY) license (http:/ / creativecommons.org/licenses/by/4.0/). 